\title{
Stem cell potency and the ability to contribute to chimeric organisms
}

\author{
Irina Polejaeva and Shoukhrat Mitalipov ${ }^{1}$ \\ Department of Animal, Dairy, and Veterinary Sciences, Utah State University, Logan, Utah 84321, USA and ${ }^{1}$ Oregon \\ National Primate Research Center, Oregon Health and Science University, Beaverton, Oregon 97006, USA \\ Correspondence should be addressed to I Polejaeva; Email: irina.polejaeva@usu.edu, S Mitalipov; Email: mitalipo@ohsu.edu
}

\begin{abstract}
Mouse embryonic chimeras are a well-established tool for studying cell lineage commitment and pluripotency. Experimental chimeras were successfully produced by combining two or more preimplantation embryos or by introducing into host embryo cultured pluripotent embryonic stem cells (ESCs). Chimera production using genetically modified ESCs became the method of choice for the generation of knockout or knockin mice. Although the derivation of ESCs or ESC-like cells has been reported for other species, only mouse and rat pluripotent stem cells have been shown to contribute to germline-competent chimeras, which is the defining feature of ESCs. Herein, we describe different approaches employed for the generation of embryonic chimeras, define chimera-competent cell types, and describe cases of spontaneous chimerism in humans. We also review the current state of derivation of pluripotent stem cells in several species and discuss outcomes of various chimera studies when such cells are used.
\end{abstract}

Reproduction (2013) 145 R81-R88

\section{Developmental potential and embryonic chimerism}

The term 'chimerism' is derived from the Greek Xí $\mu \alpha \iota \rho \alpha$, meaning 'she-goat or monster', a monstrous fire-breathing creature composed of the parts of three animals: a lion, a serpent, and a goat. In biology, the term 'chimera' usually refers to a single organism composed of two or more different populations of genetically distinct cells originated from different zygotes. Typically, experimental embryonic chimeras are formed by the aggregation of two or more whole early cleaving embryos or by combining isolated blastomeres from two or more embryos. The contribution level of each parental cell type in the tissues and organs of chimeric offspring can vary. For example, a chimeric organism could potentially consist of an equal mixture of parental embryonic cells in all cell and tissue types or contain only a limited contribution of one of the genotypes in some tissues (microchimerism (Mc)).

The level of contribution in embryonic chimeras largely depends on the developmental potency of parental cells. Mammalian development originates from a state of totipotency, an attribute of zygotes and early cleaving blastomeres. Totipotency is defined as the ability of a single cell to divide and produce all the differentiated cells of an organism including extraembryonic (placental) and embryonic tissues (embryo proper) (Mitalipov \& Wolf 2009). As development advances, totipotent cells undergo differentiation and segregation into developmentally more restricted cell lineages. The first visual differentiation of an embryo takes place during the formation of a blastocyst, a stage consisting of two cell lineages: the inner cell mass (ICM) and the trophectoderm (TE). The ICM further segregates into the epiblast and primitive endoderm (PE), which subsequently form the embryo proper and parts of the yolk sac respectively. The TE contributes to the extraembryonic tissues including primary and secondary giant cells, spongiotrophoblast, and chorionic ectoderm. The epiblast and its in vitro counterparts, embryonic stem cells (ESCs), are termed pluripotent based on their ability to give rise to all three germ layers (ectoderm, mesoderm, and endoderm) of the embryo proper. However, the epiblast and ESCs also contribute to some extraembryonic tissues (Beddington \& Robertson 1989). Early studies have demonstrated that in addition to the embryo proper, mouse ESCs contribute to the amnion and the extraembryonic mesoderm of allantois, chorion, and yolk sac. Since this phenomenon has not been thoroughly investigated, it could be one of the defining factors responsible for chimera competency of ESCs. It is also important to note that developmental potential of ESCs is more restricted than that of whole ICMs (Rossant \& Lis 1979). As previously stated, it is well documented that in addition to the epiblast lineage, early ICM cells also contribute to the PE that subsequently forms part of the yolk sac. In contrast, 
ESCs and other pluripotent cell types are not capable of forming the PE and rely on the host embryo complementation for this extraembryonic compartment in chimeras.

The early experimental mouse chimeras were produced in the 1960s by aggregating two or more whole 8-cell embryos resulting in normal-sized mice whose tissues consist of a mixture of parental embryos (Tarkowski 1961, Mintz 1962). Chimerism in such embryos extends to the epiblast, the TE, and the PE. Mouse aggregation chimeras have provided an invaluable tool to study important questions in developmental biology, cell lineage commitment, genetics, and immunology (McLaren 1976a, 1976b, Tarkowski 1998, Alexandre 2001). Gardner (1968) was able to produce mouse chimeras by an injection of isolated ICM cells into a host blastocyst cavity. Later on, as more mouse chimeric studies were conducted, it became apparent that despite introduction into the 8-cell, morula, or blastocyst host embryos, the ICM contribution was always limited to the epiblast and the PE (Tam \& Rossant 2003). Since the earlier studies were conducted, a range of other pluripotent cell types has been shown to contribute to mouse embryo proper chimeras. Specifically, pluripotent teratocarcinoma cells (Mintz \& Illmensee 1975), ESCs (Bradley et al. 1984), primordial germ cells (Matsui et al. 1992), reprogrammed to pluripotency by somatic cell nuclear transfer ESCs (ntESCs; Wakayama et al. 2001), and induced pluripotent stem cells (iPSCs; Okita et al. 2007) can also contribute to chimeras. The combination of host and donor cell types capable of forming mouse chimeras is illustrated in Fig. 1.

Mouse chimeras can also be successfully produced with tetraploid host embryos. Experimentally produced tetraploid embryos can be derived by the fusion of mouse 2-cell embryos. Such embryos are not capable of forming viable offspring; however, they have an ability to contribute to functional extraembryonic tissues. When ESCs are introduced into mouse tetraploid embryos, they colonize the embryo proper, the amnion, the allantois, and the mesoderm layer of the yolk sac, while tetraploid cells are restricted to the other remaining extraembryonic tissues resulting in almost completely ESC-derived postnatal offspring (Nagy et al. 1993). Mutant and wildtype embryos have also been used for aggregation chimeras to pinpoint timing and nature of developmental defects in mutant embryos. The failure or abnormal contribution of defective embryonic cells to a particular lineage, tissue, or organ in chimeras can be complemented and rescued by wild-type embryo cells, thus allowing development to continue (Tam \& Rossant 2003). ESC-tetraploid chimeras can be particularly useful to study defects in the development of extraembryonic lineages. A classical example is the targeted mutation of Hnf4, a gene encoding for the transcription factor known as hepatocyte nuclear factor 4. Homozygous mutant (Hnf4 ${ }^{-1-}$ ) embryos fail to complete gastrulation, resulting in early embryonic arrest (Chen et al. 1994). Rescue of the extraembryonic compartment in chimeras by tetraploid host embryos allowed $\mathrm{Hnf}^{-1-}$ ESCs to undergo normal gastrulation,

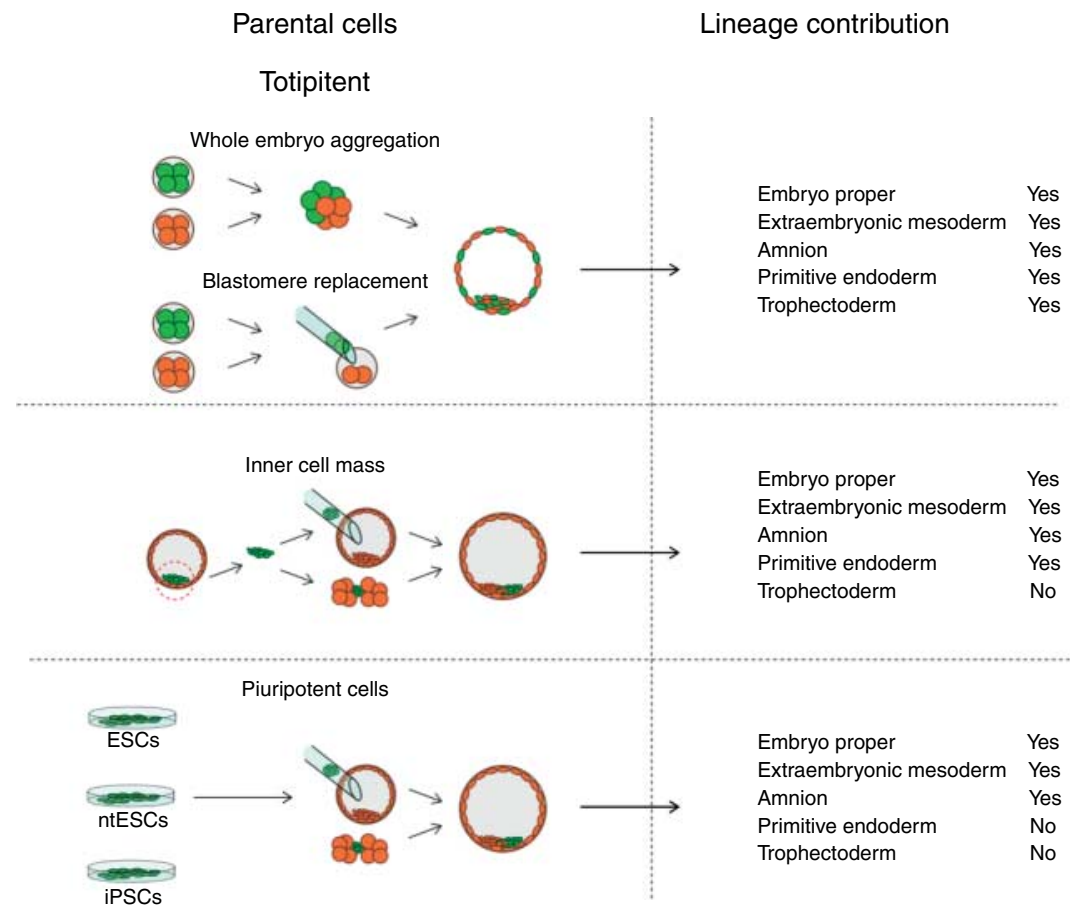

Figure 1 Developmental potential and contribution to chimeras. Aggregation of whole embryos or totipotent blastomeres from early embryos results in chimeras with contribution to all embryonic (embryo proper) and extraembryonic lineages. Whole mouse ICMs injected into blastocysts or cleaving embryos participate in the formation of the embryo proper and most extraembryonic tissues in chimeras except the TE lineage. Contribution of pluripotent ESCs, ntESCs, or iPSCs in chimeras is restricted to the embryo proper, amnion, and extraembryonic mesoderm of the allantois, chorion, and visceral yolk sac. 
suggesting that $\mathrm{Hnf}^{-1-}$ defects at this stage of development are primarily affecting the PE lineage (Duncan et al. 1997).

While conventional chimeras are generated by the aggregation of embryos or embryonic cells derived from the same developmental stage, chimeric offspring can be produced by mixing embryonic cells from different developmental stages (Gearhart \& Oster-Granite 1981, Nagashima et al. 2004). As pointed above, isolated ICMs can contribute to chimeras not only when injected into the blastocoelic cavity of host blastocysts, but also when introduced into 8-cell- or morula-stage embryos (Butler et al. 1987, Polzin et al. 1987, Roth et al. 1989, Nagy et al. 1990, Picard et al. 1990).

It is critical to utilize genetic, biochemical, or phenotypic markers that would allow to distinguish the contribution of parental cells in a chimeric organism. Aggregation of embryos with a distinct coat color pattern (different strain of mice) has been routinely used as one of the key markers of chimerism during early research studies on chimeras. Other common markers used initially were the electrophoretic variants of the housekeeping enzyme glucose-6-phosphate isomerase (GPI). The major limitation of the GPI is the inability to detect variants at the spatial histological level (Buehr \& McLaren 1981). An ideal marker would detect a putative chimera at the single-cell level in situ. The first generation of genetic markers that were used to distinguish cells of different origins in chimeras was strain-specific DNA satellite markers (Rossant et al. 1983). These markers allowed cell lineage tracking based on in situ hybridization of histological samples. At the present time, the most broadly utilized markers are the $\beta$-galactosidase enzyme encoded by the Escherichia coli lac $Z$ gene and the green fluorescent protein (GFP). Expression of lac $Z$ can be detected by histochemical staining, while GFP expression detection requires epifluorescent microscopy. Since such transgenes are not readily available for other mammals, additional genetic markers such as microsatellites, also known as short tandem repeats, can be employed (Tachibana et al. 2012).

\section{Chimera-competent pluripotent stem cells in the mouse}

As discussed, the chimera assay is used as an ultimate pluripotency test for experimentally cultured mouse pluripotent stem cells, such as ESCs and, more recently, iPSCs. While natural pluripotent cells within developing embryos exist transiently, when isolated and explanted using adaptive culture conditions, they can grow in vitro but remain pluripotent. Embryo-derived stem cells termed ESCs can be propagated indefinitely, providing an unlimited source of pluripotent cells. When a few ESCs are reintroduced into a host embryo, they can resume normal developmental program and contribute to all tissues and organs of chimeric offspring. ESCs can be readily isolated using standard techniques, but only from a very few so-called 'permissive' mouse strains (129, C57BL/6, and BALB/C).

Pluripotent cell lines have also been derived from postimplantation mouse epiblasts (days E5.5-7.5) and were termed EpiSCs (Tesar et al. 2007). Such cells are morphologically distinct from mouse ESCs and also differ based on their growth and culture requirements (Tesar et al. 2007). The fundamental distinction from mouse ESCs is that EpiSCs do not contribute to chimeras (Rossant 2008, Guo et al. 2009). Speculation is that EpiSCs represent more restricted ('primed') pluripotent cells while ESCs symbolize a developmentally more potent ('naive') state of pluripotency (Nichols \& Smith 2009). The inability of EpiSCs to form chimeras could simply be due to their failure to contribute to the vital extraembryonic tissues. As we have discussed, the epiblast and ESCs colonize the amnion, the allantois as well as the mesoderm layer of the yolk sac. It is conceivable that their initial contribution to the extraembryonic niche is required for subsequent development into the lineages of the embryo proper.

Experimental pluripotent stem cells can also be produced by reprogramming somatic cells. Reprogrammed somatic cells may have a particularly important role in future clinical applications of autologous cell replacement therapies since a patient's own cells would evade host immune-based rejection. Reprogramming of somatic cells to pluripotency can be achieved using two alternative approaches: i) by direct reprogramming into iPSCs or ii) by somatic cell nuclear transfer into ntESCs. Direct reprogramming by current techniques operates by delivering and expressing exogenous genes known to be essential for pluripotency (Takahashi \& Yamanaka 2006). Somatic cell nuclear transfer, often referred to as cloning, is based on oocyte-assisted reprogramming, where the cytoplasm of an enucleated oocyte delivers the essential epigenetic and cytoplasmic factors that support natural reprogramming processes and thus recapitulates the normal development of totipotent and pluripotent cells.

Both mouse ntESCs and iPSCs share the defining feature of embryo-derived ESCs, i.e. their ability to contribute to chimeras (Fig. 2). In addition, ntESCs and iPSCs have met the current most stringent pluripotency assays and have generated all stem cell-derived mice following tetraploid complementation (Boland et al. 2009, Lin et al. 2010). However, when ntESCs and iPSCs were derived from genetically identical donor cells and then compared for their ability to generate mice through tetraploid embryo complementation, only ntESCs resulted in a successful outcome; iPSCs failed to produce whole iPSC mice. This demonstrates that nuclear transfer can generate ESC-equivalent pluripotent stem cells more effectively than factor-based reprogramming (Jiang et al. 2011). 


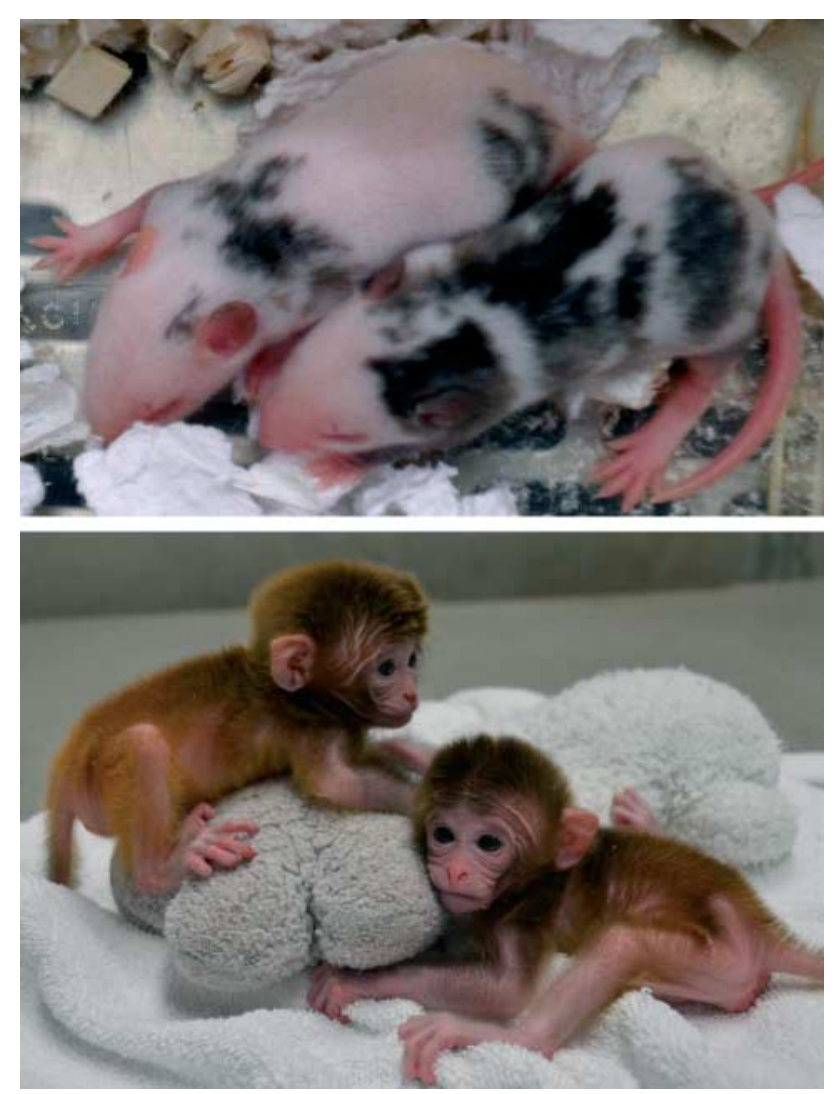

Figure 2 Mouse and rhesus monkey chimeras. (Upper panel) Mouse chimeric pups produced with iPSCs in the Mitalipov Laboratory (unpublished results). iPSCs were derived by the transduction of skin fibroblasts isolated from the C57BL/6 (black) strain with lentiviral vectors carrying Yamanaka's reprogramming factors (Oct4, Sox2, KIf4, and c-Myc). To evaluate developmental competence, approximately eight to ten isolated iPSCs were injected into cleaving 4- to 8-cell embryos from ICR (albino) mice and transplanted into the recipients. Note the black coat color spots in offspring, demonstrating the contribution of iPSCs to chimeras. (Lower panel) Roku and Hex, chimeric rhesus infants each produced by the aggregation of six individual 4-cell embryos (Tachibana et al. 2012). Extensive contribution of parental embryos in the blood and extraembryonic tissues was confirmed using microsatellite and mtDNA genotyping. In addition, sex-specific PCR, G-banding, and fluorescent in situ hybridization (FISH)-based cytogenetic assays detected the presence of both male $(X Y)$ and female $(X X)$ cells in Roku, suggesting sex chimerism.

\section{Experimental embryonic chimeras in other species}

Aggregation of early-cleaving embryos (or isolated blastomeres) have resulted in the birth of chimeric animals in a number of mammals including sheep (Tucker et al. 1974), rats (Mayer \& Fritz 1974), rabbits (Gardner \& Munro 1974), cattle (Brem et al. 1984), and, more recently, in nonhuman primates (Tachibana et al. 2012). Moreover, aggregation of goat and sheep early embryos or injection of goat ICMs into sheep blastocysts can also result in a birth of live interspecies chimeras (Fehilly et al. 1984, 1985, Polzin et al. 1987, Roth et al. 1989). Chimeric cattle fetuses were produced by the aggregation of embryos generated through somatic cell nuclear transfer with IVF embryos (Stice et al. 1996).

In the rhesus monkey, transplantation of ICMs into blastocysts will not result in efficient integration into the host ICM (Tachibana et al. 2012). Unlike mouse ICM chimeras, monkey donor and host ICMs develop into separate offspring while sharing the TE compartment of host blastocysts. Thus, whole ICM injection into a host blastocyst will often produce twin fetuses. Analysis of such rhesus fetuses demonstrated limited chimerism in their bodies (embryo proper; Tachibana et al. 2012). Specifically, chimerism was only detected in livers and spleens that possibly could result from the exchange of blood and blood stem cells through placental perfusions. However, chimerism in the extraembryonic compartment consisting of chorionic and amniotic tissues was extensive, indicating that both the host embryo and injected ICMs contributed to these lineages.

To investigate possible mechanisms responsible for the inability of injected ICMs to incorporate with host ICMs and form embryo proper chimeras, monkey blastocysts and ICMs were analyzed for lineage segregation. Cells within an ICM in mouse preimplantation-stage (E3.5) blastocysts are relatively homogeneous and not visibly differentiated into epiblast and PE fates. Such segregation is apparent in peri-implantation blastocysts (E4.5), where the layer of the PE is spatially separated and covers underlying epiblast cells (Cockburn \& Rossant 2010). This segregation coincides with a significant decline in the ability of host ICM to incorporate injected pluripotent cells and form mouse chimeras (Ohta et al. 2008).

Analysis of preimplantation blastocysts has demonstrated that monkey ICMs have already segregated into the epiblast and PE lineages. Even in early blastocysts, ICMs consisted of a cluster of NANOG-positive epiblast that was covered by GATA6-positive PE cells. This event likely prevents efficient aggregation of injected ICMs or ESCs with donor ICMs and the formation of embryo proper chimeras.

In contrast to ICMs, monkey chimeras were efficiently produced by the aggregation of cleaving 4-cell embryos (Fig. 2). It was demonstrated that blastomeres of the 4-cell monkey embryos are totipotent since a single blastomere can support full-term development (Chan et al. 2000). Between three and six individual 4-cell monkey embryos were aggregated together and 14 resulting blastocysts were transplanted into five recipients (Tachibana et al. 2012). Remarkably, all the five recipients became pregnant: two females carried singletons, another two carried twins, and one recipient had quadruplets. Such high pregnancy $(100 \%)$ and implantation rates $(10 / 14$ or $71 \%)$ were remarkable, considering that average rhesus embryo transfer outcomes with nonchimeric embryos do not exceed $36 \%$ pregnancy and $17 \%$ implantation rates (Wolf et al. 2004). Since chimeric blastocysts consisted of much higher cell counts (double or triple of regular numbers), 
it is possible that sufficient cell numbers in preimplantation embryos are critical for pregnancy initiation.

When several midgestation rhesus fetuses were recovered and analyzed for the genetic contribution of parental embryos, all offspring were confirmed to be chimeras. Remarkably, chimerism was detected in all the tested tissues and organs including placenta, spleen, reproductive tract, bladder, pancreas, stomach, small intestine, adrenal gland, kidney, and muscle. Since chimeric embryos were generated by aggregating together of three or more cleaving embryos, some fetuses displayed the contribution of multiple parental genotypes. Chimerism was also confirmed in three live born infants that were phenotypically normal males (Fig. 2). However, detailed cytogenetic analysis of blood showed that one infant contained both male $(X Y)$ and female $(\mathrm{XX})$ cells, confirming sex chimerism.

\section{ESCs in other species}

Although derivation of ESCs or ESC-like cells expressing pluripotency markers has been reported for several species, only mouse and rat ESCs have so far been shown to contribute to germline chimeras. The first germline-competent rat ESCs were recently derived using modified culture conditions ( $\mathrm{Li}$ et al. 2008). These cells express typical pluripotency markers and retain the capacity to differentiate into derivatives of all the three germ layers. Most importantly, they efficiently induce chimeras when reintroduced into early-cleaving embryos (Li et al. 2008). Rat ESCs were also capable of contributing to the germline and some extraembryonic lineages (Demers et al. 2011).

It is currently assumed that species-specific differences in ESC maintenance and culture between mouse and farm animals are the posing factors challenging the identification and derivation of putative ESCs. As an example, enzymatic dissociation of cattle ESCs results in cell death or differentiation (Stice et al. 1996, Cibelli et al. 1998). In addition, there is inconsistency among proposed markers for defining genuine bovine ESCs (Malaver-Ortega et al. 2012). It has been reported that livestock ESCs share some morphologic features with mouse EpiSCs rather than with mouse ESCs. These unique characteristics include flat epithelial-like cells that have low tolerance to enzymatic single-cell dissociation (Tesar et al. 2007). Several studies have reported the isolation of bovine ESC-like cells that are capable of contributing to the somatic tissues in chimeric offspring (Saito et al. 1992, Cibelli et al. 1998). Putative ESCs were also described from porcine blastocysts and have been shown to contribute to some somatic tissues in chimeras (Wheeler 1994, Chen et al. 1999, Brevini et al. 2010, Vassiliev et al. 2010). There was no germline contribution of ESCs documented in these chimeras. Caprine and ovine embryo-derived cell lines have also been isolated, however pluripotency was not tested in chimeras (Notarianni et al. 1991, Wells et al. 1997, Dattena et al. 2006, Pawar et al. 2009, Behboodi et al. 2011, Kumar De et al. 2011).

Recent advances in iPSC technology have opened new opportunities for the generation of pluripotent stem cells from many species including rat (Liao et al. 2009), rhesus monkey (Liu et al. 2008), cattle (Han et al. 2011), sheep (Liu et al. 2012), and pig (Ezashi et al. 2009, Wu et al. 2009). Porcine iPSCs were recently reported to induce chimeras contributing to multiple tissues that represented all the three germ layers (West et al. 2010). Fujishiro et al. (2012) demonstrated the generation of naive-like porcine iPSCs also capable of contributing to a variety of organs in chimeric fetuses (head, branchial arch, atrium, ventricle, liver, and limb bud). However, no germline contribution has been observed.

\section{Chimerism in humans}

Embryonic chimerism in humans generally occurs by the spontaneous aggregation of two different zygotes or embryos. Lacking the visible features of chimerism, the condition goes underdiagnosed in most cases. Therefore, reported cases of chimerism are generally those associated with either developmental anomalies or genotype/sex discordance (Boklage 2006). One classic example of tetragametic chimerism was a woman waiting for organ donation from her biological children. However, the histocompatibility testing indicated that the children were of different genotypes. She was later confirmed to be a germline chimera producing two different germ cell populations (Yu et al. 2002). Interestingly, she was phenotypically normal $\mathrm{XX} / \mathrm{XX}$ chimera with no detectable chimerism in her peripheral blood.

Infertility treatments by IVF could potentially increase the risk of spontaneous tetragametic chimerism. Typically, improved pregnancy rates are achieved by placing more than one embryo into a patient. This can result in up to 30- to 35-fold increase in dizygotic twin deliveries. Multiple embryo transfers could also lead to the increased risk of chimerism (Strain et al. 1998).

Human chimerism can also be caused by the aggregation of fertilized embryos with unfertilized parthenogenetic or androgenetic embryos or by aggregation with the fertilized second polar body (Strain et al. 1995, Malan et al. 2006).

The term 'microchimerism' (Mc) refers to a small population of donor cells in the body (fewer than 1 in 100 cells; Gammill \& Nelson 2010). Naturally acquired Mc originates primarily from fetal cells in the mother during pregnancy (fetal Mc) or maternal cells in her children (maternal Mc). Exchange of hematopoietic and other cells between twin fetuses can also result in Mc (De Moor et al. 1988). Feto-maternal cell exchange starts as early as six weeks of gestation (Ariga et al. 2001) and increases as pregnancy progresses. At 36 weeks of 
gestation, pregnant women have detectable fetal cells in their circulation. After delivery, the presence of fetal cells in a mother rapidly declines. However, sensitive PCR assays have shown that between 30 and $50 \%$ of women carry detectable fetal cells in the blood and hematopoietic tissues (e.g. spleen and lymph nodes) for several months and, in some cases, for decades postpartum (Evans et al. 1999). Most of the fetal origin cells in women express CD45, the common leukocyte antigen, indicating a likely hematopoietic origin. Y-chromosome in situ hybridization techniques identified male fetal origin cells in lung, lymph note, skin, thyroid, kidney, liver, and heart of postpartum women (Koopmans et al. 2008). The persistence of fetal cells long term in the maternal environment strongly indicates that this population contains stem cells, termed pregnancyassociated progenitor cells (PAPCs; Khosrotehrani \& Bianchi 2005). One possible origin of PAPCs is fetal hematopoietic stem cells (HSCs) as the placenta has two to four times more HSCs than other hematopoietic tissues (e.g. liver or yolk sac) (Alvarez-Silva et al. 2003). However, Mc is not limited to the hematopoietic lineage. For example, differentiated maternal origin cells were found among hepatocytes in the liver, renal tubular cells in the kidney and $\beta$-islet cells in the pancreas (Oliver-Krasinski \& Stoffers 2008). Male mesenchymal stem cells (presumably fetal origin) were found in bone marrow samples obtained from women who had sons from 13 to 51 years of age (O'Donoghue et al. 2004).

The widespread presence of maternal and fetal Mc in humans in a variety of tissues and organs raises some questions about the biological significance of this phenomenon (Oliver-Krasinski \& Stoffers 2008). Mouse studies have suggested that fetal cells in postpartum females may be involved in tissue repair. For example, fetal cells migrated to injured liver, heart, and brain tissues (Zeng et al. 2010, Kara et al. 2012).

\section{Conclusions}

Naturally occurring embryonic chimeras in mammals are rare; however, experimental induction of chimeric animals by mixing early embryonic cells has gained a lot of momentum and is currently being used in biomedical research for potency determination of various cell types. Mouse chimeras in particular with ESCs have become a revolutionary assay to study the gene function in knockout models. The chimera assay is the most rigorous and ultimate measure of pluripotency in experimental pluripotent cells derived by the reprogramming of somatic cells. Specifically, tetraploid chimeras are considered as the most comprehensive test, as it enables the production of whole stem cell-derived mouse offspring. Chimerism in humans is a much more common phenomenon than originally thought. Particularly, Mc resulting from mutual penetration of fetal and maternal cells is common in children and their mothers.

\section{Declaration of interest}

The authors declare that there is no conflict of interest that could be perceived as prejudicing the impartiality of the research reported.

\section{Funding}

This work was supported by grants from the National Institutes of Health HD063276, HD057121, HD059946, EY021214, and 8P51OD011092 and funds from the Leducq Fondation to $S$ Mitalipov. I Polejaeva was supported by the Utah Science Technology and Research Initiative and Utah Multidisciplinary Arrhythmia Consortium.

\section{Acknowledgements}

The authors would like to acknowledge Drs Masahito Tachibana and Eunju Kang for assistance in writing this review and for providing with illustrative materials. We are grateful to Dr Thomas Bunch for his helpful discussions and critical reading of the manuscript.

\section{References}

Alexandre H 2001 A history of mammalian embryological research. International Journal of Developmental Biology 45 457-467.

Alvarez-Silva M, Belo-Diabangouaya P, Salaun J \& Dieterlen-Lievre F 2003 Mouse placenta is a major hematopoietic organ. Development 130 5437-5444. (doi:10.1242/dev.00755)

Ariga H, Ohto H, Busch MP, Imamura S, Watson R, Reed W \& Lee TH 2001 Kinetics of fetal cellular and cell-free DNA in the maternal circulation during and after pregnancy: implications for noninvasive prenatal diagnosis. Transfusion 41 1524-1530. (doi:10.1046/j.1537-2995.2001. 41121524.x)

Beddington RS \& Robertson EJ 1989 An assessment of the developmental potential of embryonic stem cells in the midgestation mouse embryo. Development 105 733-737.

Behboodi E, Bondareva A, Begin I, Rao K, Neveu N, Pierson JT, Wylie C, Piero FD, Huang YJ, Zeng W et al. 2011 Establishment of goat embryonic stem cells from in vivo produced blastocyst-stage embryos. Molecular Reproduction and Development 78 202-211. (doi:10.1002/mrd.21290)

Boklage CE 2006 Embryogenesis of chimeras, twins and anterior midline asymmetries. Human Reproduction 21 579-591. (doi:10.1093/humrep/ dei370)

Boland MJ, Hazen JL, Nazor KL, Rodriguez AR, Gifford W, Martin G, Kupriyanov S \& Baldwin KK 2009 Adult mice generated from induced pluripotent stem cells. Nature 461 91-94. (doi:10.1038/nature08310)

Bradley A, Evans M, Kaufman MH \& Robertson E 1984 Formation of germline chimaeras from embryo-derived teratocarcinoma cell lines. Nature 309 255-256. (doi:10.1038/309255a0)

Brem G, Tenhumberg H \& Krausslich H 1984 Chimerism in cattle through microsurgical aggregation of morulae. Theriogenology 22 609-613. (doi:10.1016/0093-691X(84)90061-X)

Brevini TA, Pennarossa G, Attanasio L, Vanelli A, Gasparrini B \& Gandolfi F 2010 Culture conditions and signalling networks promoting the establishment of cell lines from parthenogenetic and biparental pig embryos. Stem Cell Reviews 6 484-495. (doi:10.1007/s12015-0109153-2)

Buehr M \& McLaren A 1981 An electrophoretically detectable modification of glucosephosphate isomerase in mouse spermatozoa. Journal of Reproduction and Fertility 63 169-173. (doi:10.1530/jrf.0.0630169)

Butler JE, Anderson GB, BonDurant RH, Pashen RL \& Penedo MC 1987 Production of ovine chimeras by inner cell mass transplantation. Journal of Animal Science 65 317-324. 
Chan AW, Dominko T, Luetjens CM, Neuber E, Martinovich C, Hewitson L, Simerly CR \& Schatten GP 2000 Clonal propagation of primate offspring by embryo splitting. Science 287 317-319. (doi:10.1126/science.287. 5451.317)

Chen WS, Manova K, Weinstein DC, Duncan SA, Plump AS, Prezioso VR, Bachvarova RF \& Darnell JE Jr 1994 Disruption of the HNF-4 gene, expressed in visceral endoderm, leads to cell death in embryonic ectoderm and impaired gastrulation of mouse embryos. Genes and Development 8 2466-2477. (doi:10.1101/gad.8.20.2466)

Chen LR, Shiue YL, Bertolini L, Medrano JF, BonDurant RH \& Anderson GB 1999 Establishment of pluripotent cell lines from porcine preimplantation embryos. Theriogenology 52 195-212. (doi:10.1016/S0093691X(99)00122-3)

Cibelli JB, Stice SL, Golueke PJ, Kane JJ, Jerry J, Blackwell C, Ponce de Leon FA \& Robl JM 1998 Transgenic bovine chimeric offspring produced from somatic cell-derived stem-like cells. Nature Biotechnology 16 642-646. (doi:10.1038/nbt0798-642)

Cockburn K \& Rossant J 2010 Making the blastocyst: lessons from the mouse. Journal of Clinical Investigation 120 995-1003. (doi:10.1172/ JCl41229)

Dattena M, Chessa B, Lacerenza D, Accardo C, Pilichi S, Mara L, Chessa F, Vincenti L \& Cappai P 2006 Isolation, culture, and characterization of embryonic cell lines from vitrified sheep blastocysts. Molecular Reproduction and Development 73 31-39. (doi:10.1002/mrd.20378)

Demers SP, Desmarais JA, Vincent P \& Smith LC 2011 Rat blastocystderived stem cells are precursors of embryonic and extraembryonic lineages. Biology of Reproduction 84 1128-1138. (doi:10.1095/ biolreprod.109.082792)

De Moor G, De Bock G, Noens L \& De Bie S 1988 A new case of human chimerism detected after pregnancy: $46, \mathrm{XY}$ karyotype in the lymphocytes of a woman. Acta Clinica Belgica 43 231-235.

Duncan SA, Nagy A \& Chan W 1997 Murine gastrulation requires HNF-4 regulated gene expression in the visceral endoderm: tetraploid rescue of Hnf-4(-/-) embryos. Development 124 279-287.

Evans PC, Lambert N, Maloney S, Furst DE, Moore JM \& Nelson JL 1999 Long-term fetal microchimerism in peripheral blood mononuclear cell subsets in healthy women and women with scleroderma. Blood 93 2033-2037.

Ezashi T, Telugu BP, Alexenko AP, Sachdev S, Sinha S \& Roberts RM 2009 Derivation of induced pluripotent stem cells from pig somatic cells. PNAS 106 10993-10998. (doi:10.1073/pnas.0905284106)

Fehilly CB, Willadsen SM \& Tucker EM 1984 Interspecific chimaerism between sheep and goat. Nature 307 634-636. (doi:10.1038/307634a0)

Fehilly CB, Willadsen SM, Dain AR \& Tucker EM 1985 Cytogenetic and blood group studies of sheep/goat chimaeras. Journal of Reproduction and Fertility $\mathbf{7 4}$ 215-221. (doi:10.1530/jrf.0.0740215)

Fujishiro SH, Nakano K, Mizukami Y, Azami T, Arai Y, Matsunari H, Ishino R, Nishimura T, Watanabe $\mathbf{M}$, Abe T et al. 2012 Generation of naive-like porcine-induced pluripotent stem cells capable of contributing to embryonic and fetal development. Stem Cells and Development [in press]. (doi:10.1089/scd.2012.0173)

Gammill HS \& Nelson JL 2010 Naturally acquired microchimerism. International Journal of Developmental Biology 54 531-543. (doi:10.1387/ijdb.082767hg)

Gardner RL 1968 Mouse chimeras obtained by the injection of cells into the blastocyst. Nature 220 596-597. (doi:10.1038/220596a0)

Gardner RL \& Munro AJ 1974 Successful construction of chimaeric rabbit. Nature 250 146-147. (doi:10.1038/250146a0)

Gearhart J \& Oster-Granite ML 1981 Reproduction in a population of chimeric mice: relationship of chromosomal sex to functional germ cells and proportions of chimeric components in several tissues. Biology of Reproduction 24 713-722. (doi:10.1095/biolreprod24.4.713)

Guo G, Yang J, Nichols J, Hall JS, Eyres I, Mansfield W \& Smith A 2009 Klf4 reverts developmentally programmed restriction of ground state pluripotency. Development 136 1063-1069. (doi:10.1242/dev.030957)

Han X, Han J, Ding F, Cao S, Lim SS, Dai Y, Zhang R, Zhang Y, Lim B \& Li N 2011 Generation of induced pluripotent stem cells from bovine embryonic fibroblast cells. Cell Research 21 1509-1512. (doi:10.1038/ cr.2011.125)
Jiang J, Ding G, Lin J, Zhang M, Shi L, Lv W, Yang H, Xiao H, Pei G, Li Y et al. 2011 Different developmental potential of pluripotent stem cells generated by different reprogramming strategies. Journal of Molecular Cell Biology 3 197-199. (doi:10.1093/jmcb/mjr012)

Kara RJ, Bolli P, Karakikes I, Matsunaga I, Tripodi J, Tanweer O, Altman P, Shachter NS, Nakano A, Najfeld V et al. 2012 Fetal cells traffic to injured maternal myocardium and undergo cardiac differentiation. Circulation Research 110 82-93. (doi:10.1161/CIRCRESAHA.111.249037)

Khosrotehrani K \& Bianchi DW 2005 Multi-lineage potential of fetal cells in maternal tissue: a legacy in reverse. Journal of Cell Science $\mathbf{1 1 8}$ 1559-1563. (doi:10.1242/jcs.02332)

Koopmans M, Kremer IC, Hovinga HJ, Baelde MS, Harvey E, de Heer E, Bruijn JA \& Bajema IM 2008 Chimerism occurs in thyroid, lung, skin and lymph nodes of women with sons. Journal of Reproductive Immunology 78 68-75. (doi:10.1016/j.jri.2008.01.002)

Kumar De A, Malakar D, Akshey YS, Jena MK \& Dutta R 2011 Isolation and characterization of embryonic stem cell-like cells from in vitro produced goat (Capra hircus) embryos. Animal Biotechnology 22 181-196. (doi:10.1080/10495398.2011.622189)

Li P, Tong C, Mehrian-Shai R, Jia L, Wu N, Yan Y, Maxson RE, Schulze EN, Song H, Hsieh CL et al. 2008 Germline competent embryonic stem cells derived from rat blastocysts. Cell 135 1299-1310. (doi:10.1016/j.cell. 2008.12.006)

Liao J, Cui C, Chen S, Ren J, Chen J, Gao Y, Li H, Jia N, Cheng L, Xiao H et al. 2009 Generation of induced pluripotent stem cell lines from adult rat cells. Cell Stem Cell 4 11-15. (doi:10.1016/j.stem.2008.11.013)

Lin CJ, Amano T, Zhang J, Chen YE \& Tian XC 2010 Acceptance of embryonic stem cells by a wide developmental range of mouse tetraploid embryos. Biology of Reproduction 83 177-184. (doi:10.1095/biolreprod.110.084707)

Liu H, Zhu F, Yong J, Zhang P, Hou P, Li H, Jiang W, Cai J, Liu M, Cui K et al. 2008 Generation of induced pluripotent stem cells from adult rhesus monkey fibroblasts. Cell Stem Cell 3 587-590. (doi:10.1016/j.stem. 2008.10.014)

Liu J, Balehosur D, Murray B, Kelly JM, Sumer H \& Verma PJ 2012 Generation and characterization of reprogrammed sheep induced pluripotent stem cells. Theriogenology 77 338-346.e1. (doi:10.1016/j. theriogenology.2011.08.006)

Malan V, Vekemans M \& Turleau C 2006 Chimera and other fertilization errors. Clinical Genetics 70 363-373. (doi:10.1111/j.1399-0004.2006. 00689.x)

Malaver-Ortega LF, Sumer H, Liu J \& Verma PJ 2012 The state of the art for pluripotent stem cells derivation in domestic ungulates. Theriogenology 78 1749-1762. (doi:10.1016/j.theriogenology.2012.03.031)

Matsui Y, Zsebo K \& Hogan BL 1992 Derivation of pluripotential embryonic stem cells from murine primordial germ cells in culture. Cell 70 841-847. (doi:10.1016/0092-8674(92)90317-6)

Mayer JF Jr \& Fritz HI 1974 The culture of preimplantation rat embryos and the production of allophenic rats. Journal of Reproduction and Fertility 39 1-9. (doi:10.1530/jrf.0.0390001)

McLaren A 1976a Genetics of the early mouse embryo. Annual Review of Genetics 10 361-388. (doi:10.1146/annurev.ge.10.120176.002045)

McLaren A 1976b. In Mammalian Chimaeras. pp. 22-34. Cambridge: Cambridge University Press.

Mintz B 1962 Experimental study of the developing mammalian egg: removal of the zona pellucida. Science 138 594-595. (doi:10.1126/ science.138.3540.594)

Mintz B \& Illmensee K 1975 Normal genetically mosaic mice produced from malignant teratocarcinoma cells. PNAS 72 3585-3589. (doi:10. 1073/pnas.72.9.3585)

Mitalipov S \& Wolf D 2009 Totipotency, pluripotency and nuclear reprogramming. Advances in Biochemical Engineering/Biotechnology 114 185-199. (doi:10.1007/10_2008_45)

Nagashima H, Giannakis C, Ashman RJ \& Nottle MB 2004 Sex differentiation and germ cell production in chimeric pigs produced by inner cell mass injection into blastocysts. Biology of Reproduction $\mathbf{7 0}$ 702-707. (doi:10.1095/biolreprod.103.022681)

Nagy A, Gocza E, Diaz EM, Prideaux VR, Ivanyi E, Markkula M \& Rossant J 1990 Embryonic stem cells alone are able to support fetal development in the mouse. Development 110 815-821. 
Nagy A, Rossant J, Nagy R, Abramow-Newerly W \& Roder JC 1993 Derivation of completely cell culture-derived mice from early-passage embryonic stem cells. PNAS 90 8424-8428. (doi:10.1073/pnas.90.18. 8424)

Nichols J \& Smith A 2009 Naive and primed pluripotent states. Cell Stem Cell 4 487-492. (doi:10.1016/j.stem.2009.05.015)

Notarianni E, Galli C, Laurie S, Moor RM \& Evans MJ 1991 Derivation of pluripotent, embryonic cell lines from the pig and sheep. Journal of Reproduction and Fertility. Supplement 43 255-260.

O'Donoghue K, Chan J, de la Fuente J, Kennea N, Sandison A, Anderson JR, Roberts IA \& Fisk NM 2004 Microchimerism in female bone marrow and bone decades after fetal mesenchymal stem-cell trafficking in pregnancy. Lancet 364 179-182. (doi:10.1016/S0140-6736(04)16631-2)

Ohta H, Sakaide Y \& Wakayama T 2008 Generation of mice derived from embryonic stem cells using blastocysts of different developmental ages. Reproduction 136 581-587. (doi:10.1530/REP-08-0184)

Okita K, Ichisaka T \& Yamanaka S 2007 Generation of germline-competent induced pluripotent stem cells. Nature 448 313-317. (doi:10.1038/ nature05934)

Oliver-Krasinski JM \& Stoffers DA 2008 On the origin of the $\beta$ cell. Genes and Development 22 1998-2021. (doi:10.1101/gad.1670808)

Pawar SS, Malakar D, De AK \& Akshey YS 2009 Stem cell-like outgrowths from in vitro fertilized goat blastocysts. Indian Journal of Experimental Biology 47 635-642.

Picard L, Chartrain I, King WA \& Betteridge KJ 1990 Production of chimaeric bovine embryos and calves by aggregation of inner cell masses with morulae. Molecular Reproduction and Development 27 295-304. (doi:10.1002/mrd.1080270404)

Polzin VJ, Anderson DL, Anderson GB, BonDurant RH, Butler JE, Pashen RL, Penedo MC \& Rowe JD 1987 Production of sheep-goat chimeras by inner cell mass transplantation. Journal of Animal Science 65 325-330.

Rossant J 2008 Stem cells and early lineage development. Cell 132 527-531. (doi:10.1016/j.cell.2008.01.039)

Rossant J \& Lis WT 1979 The possible dual origin of the ectoderm of the chorion in the mouse embryo. Developmental Biology 70 249-254. (doi:10.1016/0012-1606(79)90021-6)

Rossant J, Vijh M, Siracusa LD \& Chapman VM 1983 Identification of embryonic cell lineages in histological sections of $M$. musculus in-equilibrium M. caroli chimaeras. Journal of Embryology and Experimental Morphology 73 179-191.

Roth TL, Anderson GB, BonDurant RH \& Pashen RL 1989 Survival of sheep $x$ goat hybrid inner cell masses after injection into ovine embryos. Biology of Reproduction 41 675-682. (doi:10.1095/biolreprod41.4.675)

Saito SS, Strelchenko N \& Niemann H 1992 Bovine embryonic stem cell-like cell lines cultured over several passages. Roux's Archives of Developmental Biology 201 134-141. (doi:10.1007/BF00188711)

Stice SL, Strelchenko NS, Keefer CL \& Matthews L 1996 Pluripotent bovine embryonic cell lines direct embryonic development following nuclear transfer. Biology of Reproduction 54 100-110. (doi:10.1095/ biolreprod54.1.100)

Strain L, Warner JP, Johnston T \& Bonthron DT 1995 A human parthenogenetic chimaera. Nature Genetics 11 164-169. (doi:10.1038/ ng1095-164)

Strain L, Dean JC, Hamilton MP \& Bonthron DT 1998 A true hermaphrodite chimera resulting from embryo amalgamation after in vitro fertilization. New England Journal of Medicine 338 166-169. (doi:10.1056/ NEJM199801153380305)

Tachibana M, Sparman M, Ramsey C, Ma H, Lee HS, Penedo MC \& Mitalipov S 2012 Generation of chimeric rhesus monkeys. Cell 148 285-295. (doi:10.1016/j.cell.2011.12.007)
Takahashi K \& Yamanaka S 2006 Induction of pluripotent stem cells from mouse embryonic and adult fibroblast cultures by defined factors. Cell 126 663-676. (doi:10.1016/j.cell.2006.07.024)

Tam PP \& Rossant J 2003 Mouse embryonic chimeras: tools for studying mammalian development. Development 130 6155-6163. (doi:10.1242/ dev.00893)

Tarkowski AK 1961 Mouse chimaeras developed from fused eggs. Nature 190 857-860. (doi:10.1038/190857a0)

Tarkowski AK 1998 Mouse chimaeras revisited: recollections and reflections. International Journal of Developmental Biology 42 903-908.

Tesar PJ, Chenoweth JG, Brook FA, Davies TJ, Evans EP, Mack DL, Gardner RL \& McKay RD 2007 New cell lines from mouse epiblast share defining features with human embryonic stem cells. Nature 448 196-199. (doi:10.1038/nature05972)

Tucker EM, Moor RM \& Rowson LE 1974 Tetraparental sheep chimaeras induced by blastomere transplantation. Changes in blood type with age. Immunology 26 613-621.

Vassiliev I, Vassilieva S, Beebe LF, Harrison SJ, Mcllfatrick SM \& Nottle MB 2010 In vitro and in vivo characterization of putative porcine embryonic stem cells. Cellular Reprogramming 12 223-230. (doi:10.1089/cell. 2009.0053)

Wakayama T, Tabar V, Rodriguez I, Perry AC, Studer L \& Mombaerts P 2001 Differentiation of embryonic stem cell lines generated from adult somatic cells by nuclear transfer. Science 292 740-743. (doi:10.1126/science. 1059399)

Wells DN, Misica PM, Day TA \& Tervit HR 1997 Production of cloned lambs from an established embryonic cell line: a comparison between in vivo- and in vitro-matured cytoplasts. Biology of Reproduction $\mathbf{5 7}$ 385-393. (doi:10.1095/biolreprod57.2.385)

West FD, Terlouw SL, Kwon DJ, Mumaw JL, Dhara SK, Hasneen K, Dobrinsky JR \& Stice SL 2010 Porcine induced pluripotent stem cells produce chimeric offspring. Stem Cells and Development 19 1211-1220. (doi:10.1089/scd.2009.0458)

Wheeler MB 1994 Development and validation of swine embryonic stem cells: a review. Reproduction, Fertility, and Development 6 563-568. (doi:10.1071/RD9940563)

Wolf DP, Thormahlen S, Ramsey C, Yeoman RR, Fanton J \& Mitalipov S 2004 Use of assisted reproductive technologies in the propagation of rhesus macaque offspring. Biology of Reproduction 71 486-493. (doi:10.1095/biolreprod.103.025932)

Wu Z, Chen J, Ren J, Bao L, Liao J, Cui C, Rao L, Li H, Gu Y, Dai H et al. 2009 Generation of pig induced pluripotent stem cells with a drug-inducible system. Journal of Molecular Cell Biology 1 46-54. (doi:10.1093/jmcb/mjp003)

Yu N, Kruskall MS, Yunis JJ, Knoll JH, Uhl L, Alosco S, Ohashi M, Clavijo O, Husain Z \& Yunis EJ 2002 Disputed maternity leading to identification of tetragametic chimerism. New England Journal of Medicine 346 1545-1552. (doi:10.1056/NEJMoa013452)

Zeng XX, Tan KH, Yeo A, Sasajala P, Tan X, Xiao ZC, Dawe G \& Udolph G 2010 Pregnancy-associated progenitor cells differentiate and mature into neurons in the maternal brain. Stem Cells and Development 19 1819-1830. (doi:10.1089/scd.2010.0046)

Received 8 October 2012

First decision 12 November 2012

Accepted 5 December 2012 